невеликою хронологічною різницею, як трилогії. Така трактовка допомагає осягнути направленість композиторських стильових пошуків цього періоду та значущість кожної мініатюри як мікроетапу еволюції його мислення.

Ключові слова: фортепіанні мазурки, танцювальна музика Глінки, етапи еволюції фортепіанного стилю Глінки, російський салон XIX сторіччя.

Timchenko-Byhun I. The mazurkas trilogy by Glinka of 1834-1835 years and its artistic meanings. The article is concerned with the consideration of three mazurkas by M. Glinka, created as trilogies with the small chronological difference. This interpretation helps to realize the direction of the composer's stylistic searches of this period and the importance of each miniature as a micro-stage of the evolution of his thinking.

Keywords: the piano mazurkas, the dance music by Glinka, the stages of the evolution of the piano style of Glinka, the Russian salon of the XIX century.

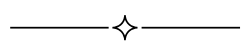

УДК 78.03

\title{
О. Муравская \\ ВОСТОЧНО-ХРИСТИАНСКАЯ КУЛЬТУРА В ОПРЕДЕЛЕНИИ ПУТЕЙ РАЗВИТИЯ ЕВРОПЕЙСКОЙ МУЗЫКАЛЬНО-ИСТОРИЧЕСКОЙ ТРАДИЦИИ
}

Статья посвящена анализу аспектов взаимодействия и взаимовлияния восточно-христианской и западноевропейской культур на базе широкого смыслового и культурно-исторического спектра понимания феномена «икономии». Сложившийся на его основе патриархально-ортодоксальный тип культуры составил базис существенного пласта европейской музыкально-исторической традиции XIX-XX ст. и ее жанровостилевых поисков.

Ключевые слова: икономия, домостроительство, патриархально-ортодоксальный тип культуры, музыка и высокий бидермайер.

В свое время известный православный святитель Николай Сербский отмечал: «все мы составляем единый огромный организм - человечество, который образовался на земле, развивался на протяжении всей истории и будет жить, пока с лица земли не исчезнет последний человек... Мы чувствуем, что человечество имеет единое тело и единую душу, понимая это метафизически и органически. И отсюда можем заключить, что все люди на земле составляют единого человека,

(C) Муравская O., 2015 
одного всечеловека, возраст которого исчисляется многими тысячами лет...» [8, с. 711]. Сказанное во многом определяет идею не только единства человечества, но и духовных оснований его культуры.

Одновременно в общем историко-культурном процессе на протяжении веков и тысячелетий каждый из народов самоопределялся в своем духовно-историческом призвании и миссии в этом мире, становясь, таким образом, участником сложного «полифонического» диалога культур, зримым проявлением которого можно считать, например, проблему соотношения «восток - запад» или «запад - восток» в рамках европейской культуры. Один из наиболее актуальных ее аспектов сконцентрирован на протяжении, по крайней мере, двух последних столетий на идее взаимодействия, а порой и противопоставления восточно-славянского либо славяно-византийского культурно-исторического типа мышления, основанного на православии, и западноевропейского, базирующегося на духовных традициях католицизма и протестантизма. Территориальное разграничение и условия социально-исторического развития привели к соответствующей дифференциации названных культур, что нашло отражение в трудах «западников» и «славянофилов», а также известных историков, культурологов - Н. Конрада, С. Аверинцева, Н. Бердяева, Г. Флоровского, Б. Свешникова, Н. Данилевского, А. Тойнби, О. Шпенглера и мн. др.

Западноевропейская модель цивилизации, складывавшаяся на протяжении многих столетий, ставила во главу угла право и рационалистический тип мышления как высшую социальную ценность. Отметим также, что западная культура ориентирована более всего на динамический образ жизни, на приоритет инициативы и на возрастающую значимую роль личности в жизни общества, личностного эго. «Если традиционная средневековая мысль... вопрос о смысле истории связывала с идеей царства божьего, то... Новое время перенесло акцент из теологической области в область социологическоантропологическую, выдвинув теорию прогресса (в идеалистическом или материалистическом ее вариантах)» [11, с. 180]. Подобного рода процессы и порожденный ими тип западной личности в совокупности привели к появлению феномена «фаустовского типа культуры» (О. Шпенглер), нередко синонимизируемого с западноевропейской культурой ХХ ст.

В Византии, позднее и на Руси, а также в западноевропейском географическом ареале, сопряженном, начиная с эпохи раннего средневековья, с восточно-христианской традицией, действовала иная циви- 
лизационная модель, базирующаяся на идеях соборности, синергии, добротолюбия, теозиса. По мнению Дмитрия Музы, «идентичность православной цивилизации определяется как идеократическая, т. е. своим основанием имеющая не натуралистические (этнические, географические, администативно-державнические), а ценностно-нормативные, духовные моменты. Их единство и трансисторическую связь образует священный текст и аскеза, задающие ощущение единого духовного смысла всех бытийных практик - сакральной, трудовой и бытовой и требующих перманентной проверки этого смысла в реалиях современности» [12]. Обозначенная цивилизационная модель, ориентированная на традиционный тип культуры, порождает и соответствующий тип личности, апеллирующий в своем идеальном проявлении к кенозису и «социальному опрощению», нестяжательству, соотносимым с образом Спасителя. Закономерным в свете сказанного можно также считать тот факт, что ключевым моментом, определяющим смысл человеческой жизни и культуры в ее православном понимании, становится (в отличие от западноевропейской идеи прогресса) Преображение. Отметим также, что подобного рода функция выступает доминирующей для музыкального искусства, которое, по мнению А. Ф. Лосева, «....приближается к «умной молитве» [14].

Вместе с тем обозначенная дифференциация названных традиций не исключает их внутренней духовной взаимосвязи и взаимовлияния. Общеизвестными в этом плане выступают тезисы о влиянии западной культуры и цивилизации на восточноевропейскую. Менее освещенным на сегодняшний день остается вопрос о влиянии восточнохристианской культуры на западную. Размышляя о православных «корняХ» русской музыкальной классики XIX в., В. В. Медушевский отмечает, что «западная музыка тоже взошла светом христианской культуры - исходного вселенского православия... Поэтому и для нее взгляд со святоотеческой высоты столь же плодотворен. Светская ее ветвь изросла из церковной музыки, заимствовав от нее критерии окрыляющей красоты и сами интонационные средства выражения... Таковому прочтению подлежат не только произведения, но и иные проявления культуры...» [10, с. 21].

Подобная открытость славяно-византийского культурно-исторического типа создает реальные возможности для его всестороннего участия в общеевропейском и мировом диалоге культур, который отнюдь не носит односторонний характер. Примеров подобного взаимодействия достаточно много. 
Учитывая христианский базис европейской культуры в целом и значимую роль в ней мистериально-литургического фактора, отметим общий для всех ранних богослужебно-певческих традиций (галльской, мозарабской, медиоланской, кельтской и др.) восточно-христианский генезис, о чем свидетельствуют собрания древних литургий, активно изучаемые и издававшиеся в XIX-XX ст., а также практика восстановления, реконструкции названных обрядовых традиций. «установленная Иисусом Христом и переданная церкви святыми его учениками и апостолами, божественная литургия в сущности одна во всех древних православных церквах Востока и Запада... Во всех древних литургиях одна апостольская основа, состоящая из следующих неизменных частей: псалмопения и пения вообще св. Песней, чтения св. Писания, поучения... молитвы возношения Св. Даров...» [13, с. 3-4].

Обрядово-литургическая общность дополняется в период раннего средневековья и позициями христианской догматики, восходившими к восточно-христианской патристике и монашеской аскетике. Сказанное соотносимо с духовными позициями Иринея Лионского, Мартина Турского, Германа Оксерского, Иоанна Кассиана Римлянина, а также с традициями Леринского и Сен-Галенского монастырей, игравшими существенную роль в раннесредневековой Галлии, а также в иных европейских регионах. Имя Иоанна Кассиана Римлянина непосредственно связано с формированием позиций семипелагианства, сопряженного с православной сотериологической концепцией, популярной не только в Галлии, но и в средневековой Британии, Ирландии. Данная концепция в свою очередь оказала существенное влияние на Патрика Ирландского и составила духовный базис феномена кельтской церкви, обширный сонм святых которой канонизирован православной церковью. Аскетические духовные подвиги ирландского монашества, особого рода интерес к греческой патристике и античной литературе на «волне» их миссионерской деятельности способствовали «возвращению» православной учености в Западную Европу и во многом определили ее духовный расцвет как в эпоху каролингского ренессанса, так и в последующие периоды развития западноевропейской культурно-исторической традиции.

Существенное место в данном процессе принадлежит византийской империи - «православно-христианской универсальной цивилизации» (по А. Тойнби), задававшей тон социально-политической, государственной и культурной жизни средневековой Европы. По 
мнению известного русского историка Ф. И. Успенского, «сохраняя в своих недрах плоды античной цивилизации, Византия служила для западноевропейских народов обильным источником знаний и просвещения. До конца XII ст. о Византии смело можно сказать, что она стояла на недосягаемой для западных народов высоте в области богословия, философии и литературы... Само богослужение латинской церкви, церковные обряды, начала церковного права - все это может быть рассматриваемо как заимствование от Византии» [16, с. 36]. Согласно выводам О. С. Воскобойникова, «несмотря на все противоречия, на непонимание, даже ненависть, несмотря, наконец, на гибельный для византийской цивилизации IV крестовый поход, византийская художественная традиция, «греческое мастерство», как говорили хронисты, оставалось для Запада предметом всеобщего восхищения, эталоном, постоянным источником вдохновения, в котором черпали как сюжеты, так и... формы изображения» [3, с. 446].

Базовые принципы византийской государственности, культуры, системы высшего образования составили основу европейской культурно-цивилизационной системы в последующие эпохи. Ведущим показателем византийской цивилизации (равно как и древнегреческой, но с «поправкой» на духовно-религиозную составляющую) выступает идея порядка (космоса), связующего земное и небесное, не допускающее их полярного противостояния и порождающее, соответственно, столь показательный для Византии феномен «симфонии властей». На музыкальном и богослужебно-певческом уровне обозначенные качества очевидны как в стройной системе византийского октоиха, ставшего основой всей христианской певческой практики, так и в аккламациях - духовно-гимническом знаке величия фигуры византийского императора. Мимезис (отражение, подобие) расценивается как кардинальное понятие византийской жизни и культуры, поскольку, согласно учению Псевдо-Дионисия, «все устроено по божественному уставу. Существование каждой вещи определяется ее чином так, что низшие чины черпают у высших силы для восхождения от дольнего к горнему» (цит. по: [9, с. 74]), определяя тем самым, одновременно, сущность и целеполагание земного пути человека в православии на уровне духовного преображения. Отметим также, что «порядок для византийцев - это еще и подчинение власти, союз и согласие между членами большого сообщества империи и ее главных составляющих - семьи и города» [4, с. 245]. Акцентирование внимания на архетипах дома, семьи, отца, иерархии в их широком понима- 
нии определяет патриархальный характер византийской культуры и цивилизации в целом, поскольку в ее рамках, по мнению С. С. Аверинцева, «бытие и быт не только не разделены, но прямо приравнены друг другу в религиозно-обрядовой модели сущего: строй бытия - от бога, но уклад быта - тоже от Бога. Поэтому самые «домашние» и «семейные», если угодно, самые «обывательские» уроки бытового благонравия лежат в той же плоскости, что и высокое видение мирового порядка» [1, с. 159]. Подобная позиция позднее также будет спроецирована на европейскую культуру последующих эпох, в частности, на бидермайер и его музыкальные проявления, акцентирующие духовную «высоту» феномена «домашней музыки» и соответствующего типа музицирования. Дополнением к сказанному становятся также такие базовые черты византийской культуры как консервативность и традиционализм. Сама традиция понималась в рамках данной культуры «как богооткровенная, как восходящая к высшему знанию, тогда как опыт по самой природе своей оказывался ограниченным, дающим знакомство лишь с поверхностными явлениями земного мира. Традиция восходила к сущности, опыт - только к феномену» [6, c. 162]. Очевидный восточно-христианский исток подобного толкования традиции во многом определял базовый тип героя византийской агиографии - «маленького человека», «нищего духом», символа «величия незаметности» (А. П. Каждан) [6, с. 203]. Сказанное также обозначило вектор и направленность развития византийской культуры, ориентированной на движение «от данности высшего идеала к последующему его упрощению и нисхождению» «от горнего к дольнему» $[7$, с. 14, 22] или, по определению С. С. Аверинцева, к «аскетическому опрощению» [1, с. 180]. Подобный творческий метод также во многом предопределен христианской подоплекой византийской культуры, ибо в ее рамках «красота не признавалась апологетами без простоты, а простота, понятая как естественность, в отличие от всего искусственного, художественного, созданного людьми, усматривалась в природе» [2, с. 82]. Обозначенный метод позднее также найдет запечатление не только в феномене «простого серьезного пения» христианской традиции, но и в его творческом освоении на уровне «широко трактованной хоральности», «новой простоты» и др. При нивелировании собственно авторского начала, что находим также и в отдельных проявлениях музыкального искусства XIX-XX ст.

Обозначенные выше качества характеристики византийской культуры, ее духовный базис, сакрализация не только властной «вер- 
тикали» с учетом духовной иерархии, но и всех сфер жизни непосредственно сопряжены с феноменом «икономии» и его русскоязычным аналогом - «домостроем». Данное понятие отличается емкостью смысла. Его генезис восходит еще к культуре Древней Греции, более конкретно - к учениям Ксенофонта и Аристотеля, в рамках которых сложилось представление об ойкономии-домострое как естественном экономическом порядке хозяйствования, в основу которого положен принцип справедливости (при абсолютном неприятии ростовщичества). Последний феномен Аристотель определяет как хрематистику - способ умножения богатства ростовщическим путем. Обозначенное учение Аристотеля «вошло в общественное сознание и определило направление экономической мысли по меньшей мере на два тысячелетия вперед» [20]. Добавим также, что оно определило не только хозяйственно-экономическую жизнь античности и последующих эпох, но и культурно-цивилизационные процессы христианского европейского региона.

Обозначенный тип экономического хозяйствования, основанный на духовно-нравственных началах, стал одним из определяющих для культуры средневековья, будучи унаследованным, прежде всего, в рамках восточно-христианской традиции. В данном случае феномен домостроительства рассматривается на уровне не только системы хозяйствования, но и богословской доктрины «господнего домостроительства». В последнем случае «икономия» представляет собой христианское учение о промысле божьем относительно мира и падшего человека, достаточно детально разработанное именно в Византии в трудах Максима Исповедника, Николая Кавасилы, Мефодия Олимпийского, Кирилла Александрийского, Григория Нисского, преп. Иоанна Дамаскина. Идея «духовного строения» составляет смысловое «ядро» и «домостроя» кекавмена. Обозначенные источники представляют собой фактическую реализацию «грандиозного религиозно-нравственного кодекса, который должен был установить и внедрить в жизнь именно идеалы мировой, семейной, общественной нравственности» [5, с. 162]. Сформированные в византийской восточно-христианской среде, идеи домостроя были унаследованы и в западноевропейской культурно-исторической традиции средневековья (Егидий Колонна, Франческо да Барберини, Бальдассаре Кастильоне, Леон Альберти, Фома Щитный, Конрад Мегенбергский и др.). Непосредственным наследником концепции домостроя по праву можно считать и Русь, где в XVI ст. появился его русский аналог, ко- 
торый стал базисом духовно-этической и хозяйственно-экономической системы России на протяжении всех последующих столетий, о чем свидетельствуют не только богословские труды Феофана Затворника, но и изыскания В. Н. Татищева, И. Т. Посошкова, А. Г. Сумарокова, М. В. Ломоносова, Д. И. Менделеева и мн. др. Для большинства из них домострой стал не только «высшей областью отношений бога к человеку» (В. В. Болотов), но и «философией человеческой жизни, занятой поисками духовных оснований повседневности. Все повседневные акты, включая и физиологические, при этом ритуализируются, поскольку точное следование ритуалам... приближает человека к основной цели его существования - духовно-телесному преображению и возвращению в «утерянный рай» [19, с. 213]. Обозначенные качества определяют не только мировоззрение и хозяйственно-экономические подходы, но и русскую культуру, в том числе и музыкальную, что особенно очевидно в первой половине XIX ст. В эпоху так называемого «русского бидермайера», в частности, в духовно-этической концепции опер М. Глинки, в камерно-вокальном наследии его современников и т. д. Таким образом, в данном качестве идея домостроя и «господнего домостроительства» являет собой христианское понимание-толкование духовного смысла человеческого бытия и преображения как базовой цели этого процесса, пронизывающей все его уровни, - от бытового, повседневного до мистериально-сакрального.

Отметим, что подобного рода духовно-мировоззренческая позиция является весьма показательной, прежде всего, для восточно-славянского региона Европы (Украина, Россия и др.), унаследовавшего традиции православия, которое составило не только его конфессиональный базис, но и основание государственно-экономической культурно-исторической традиции, сохранявшей актуальность вплоть до $\mathrm{XX}$ ст. Культурно-экономические пути Западной Европы, начиная с эпохи Ренессанса, были несколько иными. Для них показателен процесс постепенного усиления роли материального фактора, нарастания противоречий между духовной и светской властью, формирования условий для интенсивного развития капитализма и сопряженного с ним духа ростовщичества и господства хрематистики. Сказанное, как указывалось выше, вело к формированию соответствующего склада ума, мышления западного человека («фаустовского человека»), мечушегося в поисках точек соприкосновения и гармонизации духовного и физического начал. Пик подобных процессов приходится на XIX ст. 
Компенсаторную функцию в данном случае, на наш взгляд, в определенной степени выполняет культура, сохранявшая в своих разнообразных стилевых моделях патриархальный «дух» единения земного и небесного, повседневного и сакрального, обыденного и высокого, что наиболее очевидно в типологии высокого бидермайера, а также и во многих музыкальных артефактах этого периода, поскольку именно для него показательна актуализация представления о «духовно-религиозной способности музыки направлять человеческую душу к соединению с божественной ипостасью» $[18$, с. 10]. Генезис данного явления кроется, на наш взгляд, в складывавшейся, начиная еше с раннего средневековья, культурно-исторической традиции, формировавшейся на базе восточного христианства. Подобный тип культуры определяем как патриархально-ортодоксальный, сохранявший свою значимость не только в обозначенный период, но и в последующие эпохи.

В определении сушественных качеств данного феномена для нас существенным оказалось определение П. А. Флоренского, утверждавшего следующее: «культура, как свидетельствуется и этимологией, есть производное от культа, т. е. упорядочение всего мира по категориям культа. Вера определяет культ, а культ - миропонимание, из которого далее следует культура» [17, с. 39]. Представляемый тип патриархально-ортодоксальной культуры опирается на обозначенную выше концепцию «Господнего домостроительства», «домостроя» в том виде как она сложилась в восточно-христианской практике, определив не только духовное целеполагание человеческой жизни, устремленной к преображению, но и в конечном итоге гармонию земного и небесного при сакрализации-одухотворении всех уровней человеческого бытия. Архетипами подобного типа культуры являются дом, семья, отец, род, иерархия в их христианском понимании. Существенным качеством данной культуры выступает традиционализм, ориентированный на сохранность высокого смысла духовного образца, первоисточника. Изначально присущая ей гармоничность мировосприятия соседствует здесь с толерантным отношением (на раннем этапе) к иным религиозным концепциям, образуя тем самым оригинальный симбиоз идей восточного христианства, античности и языческих местных верований (кельтских, галльских, германских и др.), нивелирующих в конечном итоге национальные разграничения социума, что соответствует и апостольскому тезису «нет ни еллина, ни иудея, ни обрезания, ни необрезания, варвара, скифа, раба, свободного, но все и во всем Христос» (кол., 3,8$)$. На новом уровне данная 
идея обретает актуальность и в культуре XIX ст., в том числе и музыкальной, нацеленной на своеобразный ренессанс именно через культуру духовно-патриархальных традиций, преемственных от раннего средневековья и соотносимых с идеями восточного христианства (галликанизм, старокатоличество, феномен оксфордского движения, цецилианства и др.). Музыкальными «знаками» подобного рода культуры становится опора на типическое, общезначимое, ведущее нередко к нивелированию собственно авторского индивидуального стилевого качества, намеренному «опрощению» музыкального языка, соотносимого нередко с практикой домашнего музицирования. Актуальным интонационным «пластом» в данном случае становится церковный обиход во всем разнообразии его проявлений либо его стилизация, а также опора на сферу прикладных жанров, сохраняющих, тем не менее, в совокупности свой духовный генезис по принципу запечатления «большого» «малыми» средствами выражения, ибо «явления малого порядка - это не что иное, как грандиозность в свернутом виде» (Л. Смирнов) (цит. по: [15]).

Выделенные качества нашли запечатление в целом ряде произведений композиторов XIX-XX ст. Соотносимых, в том числе, и со стилистикой высокого бидермайера, апеллирующего в своем искусстве к старым истинам духовного порядка, в рамках которого индивид выступает частью корпоративно-соборного целого. Сочинения, связанные с данной традицией, охватывают при этом широкую жанровую сферу - от камерно-вокальных и инструментальных до оперных концепций и кантатно-ораториальных композиций, представленных в творчестве Ф. Шуберта, Р. Шумана, К. М. Вебера, Р. Вагнера, Э. Хумпердинка, С. Монюшко, К. Шимановского, в феномене французской лирической оперы (Ш. Гуно, Ж. Массне, К. Сен-Санс и др.). Предмет особого интереса в этом плане - русская и украинская музыка XIX ст., запечатлевающая отечественную духовно-патриархальную традицию во всем разнообразии и богатстве ее национальных проявлений (М. И. Глинка и его современники, В. Ребиков, Н. В. Лысенко), а также оригинальные «выходы» данной проблематики в творчестве композиторов XX ст. (С. С. Прокофьев).

Подводя итог, отметим, что обозначенные выше качества патриархально-ортодоксальной культуры во всем многообразии ее проявлений и влияний (в том числе и на западную культуру) не только свидетельствуют о существенной роли ее восточнохристианского генезиса (учение о домостроительстве и его духовно-нравственном 
базисе), но и о значимости ее показателей в современной социальноэкономической, а также художественной жизни, во многом определяющей духовно-этический облик нашего современника.

Известный экономист XX ст. Дж. Кейнс, автор нового направления в экономической теории XX ст. писал: «я предвижу, что мы будем иметь возможность вернуться к некоторым наиболее бесспорным и непреложным принципам религии и традиционной добродетели, утверждающим, что скупость - это порок, что ростовщичество недостойно человека... Мы вновь будем ценить цели выше средств и предпочитать добро пользе» [21, с. 261-262].

\section{СПИСОК ЛИТЕРАТУРЫ}

1. Аверинцев С. С. Поэтика ранневизантийской литературы / С. С. Аверинцев. - СПб. : Азбука-классика, 2004. - 480 с.

2. Бычков В. 2000 лет христианской культуры. Sub specie aesthetica: в 2 томах. - М. ; СПб. : Университетская книга, 1999. - Т. 1: Раннее христианство. Византия. $-575 \mathrm{c}$.

3. Воскобойников О. С. Тысячелетнее царство (300-1000). Очерк христианской культуры Запада / О. С. Воскобойников. - М. : Новое литературное обозрение, 2014. - 568 с.

4. Гийу А. Византийская цивилизация / А. Гийу ; пер. с фр. Д. Лоевского; предисл. Р. Блока. - Екатеринбург : Е-фактория, 2005. - 552 с.

5. Иваницкий В. Русская женщина и эпоха «домостроя» / В. Иваницкий // Общественные науки и современность. - 1995. - № 3. - С. 161-172.

6. Каждан А. П. Византийская культура (X-XII вв.) / А. П. Каждан. СПб. : Алетейя, 2006. - 280 с.

7. Колпакова Г. С. Искусство Византии. Ранний и средний периоды / Г. С. Колпакова. - СПб. : Азбука-классика, 2010. - 528 с.

8. Комашко Б. Я. История христианства и православной церкви с древности до наших дней / Б. Я. Комашко. - Донецк : Бао, 2009. - 752 с.

9. Лисичкина О. В. Мировая художественная культура: Византия / О. В. Лисичкина. - М. : АСТ: Астрель, 2005. - 270 с.

10. Медушевский В. В. Духовный анализ музыки: учебное пособие : в двух частях / В. В. Медушевский. - М. : Композитор, 2014. -632 с.

11. Можайскова И. В. Духовный образ русской цивилизации и судьба России (опыт метаисторического исследования): в 4 частях / И. В. Можайскова. - М. : Вече, 2001. - Часть 2: Русский космизм в контексте противоречий мирового развития, обусловленных господством западной цивилизации. $-480 \mathrm{c}$.

12. Муза Д. Е. Восточнохристианская цивилизация: социокультурное устроение и идентичность [Электронный ресурс] / Д. Е. Муза. - Режим доступа : lib.znate.ru/does/index-161125.html 
13. Собрание древних литургий - восточных и западных / сост. редакцией «христианского чтения», издаваемого при С.-Петербургской духовной академии. - СПб. : Типография департамента уделов, 1874. - Выпуск 1. - 200 с.

14. Суханцева В. К. Музыка как мир человека (от идеи вселенной - к философии музыки) [Электронный ресурс] / В. К. Суханцева. - Режим доступа : http://www.countries.ru/library/music_culture/mkm.htm

15. Уварова И. Вертеп - мистерия рождества [Электронный ресурс] / И. Уварова. - Режим доступа : uvarova.jimdo.com/вертеп-мистерия-рождества

16. Успенский Ф. И. История византийской империи / Ф. И. Успенский ; сост. Т. В. Мальчикова. - М. : Мысль, 1996. - 827 с.

17. Флоренский П. А., священник. Сочинения : в 4 томах / П. А. Флоренский ; сост. и общ. ред. Игумена Андроника (а. С. Трубачева), П. В. Флоренского, М. С. Трубачевой. - М. : Мысль, 1994. - Т. 1. - 797 с.

18. Холопова В. Н. Понятие «музыка» / В. Н. Холопова // Музыкальная академия. -2003 . - № 4. - С. 1-18.

19. Чумакова Т. В. Образ человека в культуре Древней Руси (опыт философско-антропологического анализа) : дис. ... д-ра философских наук : 09.00.13 - религиоведение, философия, антропология и философия культуры / Т. В. Чумакова. - СПб., 2002. - 409 с.

20. Юдина Т. Н. Домостроительство как историческая самодостаточная система хозяйства и жизнедеятельности человека [Электронный ресурс] / Юдина Т. Н. - Режим доступа : newpoliteconomy.org/publications/articles/100. pdf

21. Юдина Т. Н. Эволюция учения о домостроительстве в контексте формирования экономической системы России (вторая половина IX - начало XX века): дис. ... д-ра экономических наук : 08.00.01 - экономическая теория (область исследования - история экономической мысли) / Т. Н. Юдина. M., 2009. - 324 c.

Муравська О. Східно-християнська культура у визначенні шляхів розвитку європейської музично-історичної традиції. Стаття присвячена аналізу аспектів взаємодії та взаємовпливу східно-християнської та західноєвропейської культур на базі широкого змістовного та культурно-історичного спектру розуміння феномену «ікономії. Патріархально-ортодоксальний тип культури, що сформувався на його тлі, складає базис суттєвого пласта європейської музично-історичної традиції XIX-XX ст. та її жанрово-стильових пошуків.

Ключові слова: ікономія, домобудівництво, патріархально-ортодоксальний тип культури, музика та високий бідермаєр.

Muravskaya o. Eastern christian culture in determining how the development of the european musical and historical tradition. This article analyzes the aspects of interaction and mutual influence of the christian east and west european cultures on the basis of a broad sense and the cultural and historical spectrum of understanding 
of the phenomenon of «economia». Formed on the basis of its patriarchal orthodox type of culture was the basis of a substantial reservoir of european music and the historical tradition of XIX-XX c. And her genre-style searches.

Keywords: economia, fellowship, orthodox patriarchal type of culture, music and high biedermeier.

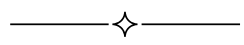

УДК 78.03(09)

\section{Н. Довгаленко \\ СЕРІЙНІ СТРУКТУРИ В КОМПОЗИЦІЯХ В. СИЛЬВЕСТРОВА}

Стаття присвячена дослідженню прийомів та принципів застосування серійної техніки у деяких творах В. Сильвестрова 1960-х років. Аналіз зроблений на матеріалі фортепіанних та камерних творів цього періоду. Своєрідність стилістики композитора проявилася в переосмислюванні прийомів серійної та додекафонної техніки і синтезі ї̈ з елементами інтонаційно-мотивної системи.

Ключові слова: серійна техніка, В. Сильвестров, шістдесятництво, український авангард.

Творчість Валентина Сильвестрова сьогодні є мистецьким явищем, в художньому світі якого знайшли своє відбиття неосяжні парадигми сучасного буття. Твори В. Сильвестрова $60-x$ років, яким присвячена запропонована розвідка, становлять перший, авангардний період його композиторського шляху. Саме в них відбувалося формування головних естетичних та стилістичних засад майбутніх досягнень. Тому метою дослідження є виявлення тих рис стилю В. Сильвестрова, що стали провідними в подальшій творчості майстра та зберегли своє значення в стильових трансформаціях наступних десятирічь. Головним же завданням цієї статті є виявлення своєрідності застосування композитором авангардних прийомів письма, а саме серійної техніки. Незважаючи на широкий перелік робіт, що в різних аспектах порушують проблематику шодо стилю В. Сильвестрова, досі не існує досліджень, які були би спрямовані на вирішення запропонованої нами проблематики. Поодинокі висловлення щодо ранніх творів В. Сильвестрова (наприклад, [3; 5]) не ставили за мету конкретизацію стилістичних ознак у використанні серійної техніки,

(C) Довгаленко Н., 2015 